\title{
Social Norms Matter: University Students' Misbehaviors in the Metro Carriage
}

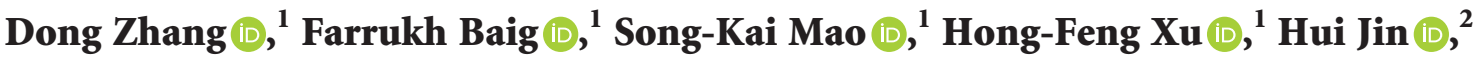 \\ and $\mathrm{Li} \mathrm{Li} \mathbb{D}^{3}$ \\ ${ }^{1}$ Department of Transportation \& Logistics, Dalian University of Technology, Dalian 116024, China \\ ${ }^{2}$ School of Rail Transportation, Soochow University, Suzhou 215131, China \\ ${ }^{3}$ School of Electronics \& Control Engineering, Chang'an University, Xi'an 710064, China
}

Correspondence should be addressed to Dong Zhang; zhangdong@dlut.edu.cn

Received 24 August 2021; Accepted 7 October 2021; Published 18 October 2021

Academic Editor: Luigi Dell'Olio

Copyright ( 92021 Dong Zhang et al. This is an open access article distributed under the Creative Commons Attribution License, which permits unrestricted use, distribution, and reproduction in any medium, provided the original work is properly cited.

Metro travelers' travel experience is highly influenced by fellow passengers' misbehaviors such as eating or littering in the carriage and sound blaster, which are common in the metro carriage. Although operators have implemented various regulations to reduce misbehavior, little theoretical research has investigated such behavior motivators to provide targeted guidelines for specific passenger segments. To this end, this study explores how demographic and perceived social norms of university students affect their misbehaviors, i.e., eating in the carriage, public display of affection, sound blaster, cross-legged sitting, leaning against the pole, and littering, in the metro carriage of Shanghai, China. With the structural equation model, it is revealed that both injunctive and descriptive norms impose significant impacts on passengers' inappropriate behaviors, with the effect of the former generally to a greater degree. Gender heterogeneity in passenger misbehavior is also observed, where males significantly perform better in eating in the carriage and cross-legged sitting. These findings may decode the underlying motivation of passenger misbehaviors and provide guidelines for effective intervention with targeted policy design and implementation.

\section{Introduction}

Metro passengers may travel a long or short distance with many others in the same carriage, where social interactions are inevitable and may significantly affect trip experience [1]. Besides the physical attributes of service quality, the social atmosphere in metro transit also has great importance in achieving passengers' high satisfaction, a critical issue of enhancing public transport attraction and promoting transit ridership [2, 3]. More importantly, a frequent appearance of unruly passengers onboard may also imply a higher likelihood of being the victim of a crime while traveling by transit. Even though a sound blaster may not be an actual threat, it could label the system's code of conduct not being enforced. Thus, it is necessary to reduce passenger misbehavior that may degrade the metro service's social environment and lead to its lousy image for current and potential passengers.
Previous studies have sufficiently considered the dysfunctional passenger's fare evasion behavior to secure the operating revenue $[4,5]$. However, misbehaviors in transit services can cause more consequences than fare evasion, as widely reported in social media. For example, BBC news magazine found that playing songs loud in public transport, mostly by young adults, can be irritating to trigger passenger conflicts [6]. A news report in Brisbane, Australia, has emphasized more passenger misbehaviors, including eating and drinking on the trains, feet/bags on seats, noise in the quiet carriage, and occupying priority seats [7]. Talking loudly on the phone, snoring, putting makeup on, eating on the train, and staring at others' phones were also observed by Jakarta's Mass Rapid Transit [8]. Chinese media highlights the misbehaviors of scrambling for seats [9], spreading false information [10], and smoking [11]. Transportation agencies are launching 
media campaigns to address the increasing number of incidents related to passengers' misbehavior, such as the courtesy campaign by CTA [12] and Enjoy and Respect campaign in Amsterdam, Netherlands [13]. Likewise, the Ministry of Transport in China regulates that eating and drinking on a subway train is uncivilized [14].

It is expensive and probably unrealistic to stop every misbehavior with penalties or other enforcement measures as metro passenger's misbehavior is sparsely distributed both spatially and temporally. Moreover, such a phenomenon can be reasonably expected to be reduced under proper guidance and regulation. In this endeavor, a thorough understanding of misbehavior's psychological determinants will help identify the underlying factors of such an idea's feasibility and may enlighten the development of effective policy plans for better public transport.

The remainder of this paper is arranged as follows: Section 2 reviews the existing literature on misbehavior and the factors in transportation and some other fields. Section 3 illustrates how the research is conducted, including the conceptual model, data collection, and analytical procedure. Section 4 reports the descriptive details of measures and results of structural equation modeling. The last section summarizes the findings and discusses the implications for public transport misbehavior regulation.

\section{Literature Review}

2.1. Misbehavior in Public Transport. Started with a negative prefix (mis-), misbehavior refers to wrong behavior, improper, or not normal and thus is not acceptable by others $[15,16]$. The discussion of the misbehavior should be set under specific contexts. For example, in economics, misbehavior mainly refers to actions that are not rational enough to maximize the player's utility [17], while in the consumer behavior field, where misbehavior is intensively discussed, consumer misbehavior can be broadly defined as behavioral acts by consumers that violate the generally accepted norms of conduct in consumption situations and disrupt the order expected in such situations $[18,19]$. Some scholars use the term antisocial behavior to refer to misbehavior in a general context from a criminology perspective. One legal meaning of antisocial behavior is defined by London-based Crime and Disorder Act (1998) as the action in a manner that causes or is likely to cause harassment, alarm, or distress to one or more people not of the same household as the defendant [20]. These various definitions refer to the demonstration of the individual's conduct, which contravenes the norms acknowledged by the general public in a specific setting such as consumption and traveling.

In public transport, since passengers from different backgrounds share the vehicle for travel, improper interaction among crowds may lead to disharmony and sometimes results in physical or verbal abuse [21]. Hence, the negative impacts of passenger's misbehavior in public transport are much likely to be inevitable. Studies have explored various types of misbehaviors in public transport settings. Salomonson and Fellesson [22] explicitly identified misbehaviors such as physical abuse, verbal abuse, threats, and violence, and the practical strategies have been adapted by staff to tackle such negative situations in Sweden. The improvement of service quality was further suggested to mitigate misbehavior issues. Moore [23] summarized issues related to passenger misbehavior in the United Kingdom-based public transport and listed misbehaviors from most annoying to less annoying and from intentional to inadvertent. Later, Moore's [20] study revealed several misbehavior types from the public transport perspective, such as shouting/swearing at the driver or others, not paying the fare, smoking, spitting, dropping litter, and pushing others. Chicago Transit Authority (CTA) prepared a well-formatted list of thirteen most observed commuter's misbehaviors from top registered complaints submitted to the transit agency via social media, calls, and emails. Besides, CTA personnel observation, together with the social media pooling responses of 5,000 urbanities, was also implied in forming a list of troublesome behaviors in public transport. The list includes not moving to the middle of a train car, sitting on the train before others get off, blocking the doors, not standing right, walking left on escalators, not moving down the platform and using all doors, eating on the train or bus, not yielding priority seats for pregnant women or disabled people or seniors, littering, playing loud music, placing bags on seats, and talking loudly on phones [24]. After that, CTA started a courtesy campaign to control the passenger's misbehavior to make the ride more comfortable and worthy $[12,25]$.

Among all types of misbehavior related to the public transport industry, fare evasion, directly related to public transport operators' revenue, received extensive attention [5]. The Australian study categorized fare evaders into four types: the accidental evader, the "It is not my fault" evader, calculated risk-taker, and career evaders [26]. Socioeconomic determinants of fare evasion were also influential in a study conducted in Belgium [27]. That study highlighted the youngster's involvement in fare evasion as higher than other age groups and suggested that the campaigning focus group be young. Given that, literature studies gave extensive attention to fare evasion and negligible focus on low-level misbehaviors, including eating in the carriage, sound blaster, and littering. This situation caused the imbalance in the transport literature dealing with passenger's misbehaviors. The recent decade brought the academicians' attention to find ways to analyze and deal with troublesome travelers in public transport $[22,28]$. However, the study on the determinants of motivating low-level misbehaviors, which are necessary to prepare effective mitigating strategies to prevent their occurrence, remained scarce.

2.2. Social Norms and Behaviors. The consistency with the publicly accepted conduct code is a golden standard for misbehavior identification. Social norms, laws, and traditions are the three principal codes [29]. As a social psychology construct, Rimal and Lapinski [29] argued that social norms originate from social negotiation and are highly contextdependent. In contrast, laws are explicitly coded prescriptions that link violations with punishments. Traditions are similar to social norms since they are both socially negotiated, though traditions are more stable. Though no generally 
acknowledged definition of social norms exists, they can be described as the behavioral influence of others. To be detailed, social norms refer to rules and standards that are understood by a group of individuals, though, unlike the law system, they influence behavior through interaction with others [30,31].

We have noted different taxonomies of social norms employed in the parallel literature [31,32]. We preferably adopted the one by Thøgersen [33] because of its simple hierarchical description. Thøgersen [33] proposed the theoretical segmentation of social norms by extending the traditional taxonomy of social norms into its subtypes. Firstly, the proposed extended taxonomy categorizes social norms into descriptive norms (DNs) and injunctive norms (INs). DN denotes the perception of what is normal to others, that is to say, what most people do. Comparatively, IN refers to the beliefs and social principles that constitute the moral approval or disapproval of one behavior, i.e., what should be done. Secondly, the IN in the extended taxonomy of Thøgersen [33] can be further divided into subjective norms (SNs) and personal norms (PNs). SN refers to the perception of social pressure where important people (peers, parents, etc.) motivate a person to deny or accomplish a behavior [34]. On the contrary, PN is defined as the selfexpectation of accomplishing or denying a specific behavior in a specific situation. To sum up, the definitions of social norms adopted in the current study are as follows:

(i) Subjective norms are norms that are enforced by the expectations of people that are important to an individual. For example, what friends/parents expect an individual to do [31, 33-35].

(ii) Personal norms are self-expectations of a specific action in a particular situation, experienced as a feeling of moral obligation. For example, what is right or wrong to do [31, 33].

(iii) Injunctive norms refer to the beliefs and social principles that constitute the moral approval or disapproval of one behavior. For example, what should be done [32, 33]. Subjective norms and personal norms are subclasses of injunctive norms.

(iv) Descriptive norms are the perceptions of normal behavior. For example, what is normal to others or what most people do [31-33].

The literature has widely discussed that social norms have demonstrable impacts on actions or behaviors [32]. Notably, in the transportation arena, the impacts of social norms have been investigated and confirmed in various topics. For example, in the context of environmentally friendly mode adoption behavior, $\mathrm{SN}$ has been discussed as one of the influencing factors affecting behavioral intentions to adopt low-carbon modes of transportation, including battery electric vehicles and hybrid electric vehicles [36-39].

Behavior change can occur through a change in social norms [40]. From the perspective of safety-related behaviors, $\mathrm{DN}$ is found to affect the drivers to be involved in distracting behaviors such as using phones and talking with other passengers [41] and pedestrians' intentions to violate the rules for road crossing [42]. Therefore, Kim [43] suggested using moral norms and legal enforcement to activate the safe behavior among young college students in preventing texting while driving in the United States. For the illegal parking behavior of free-floating bike-sharing users in China, SN was discussed as an effective measure to control such misbehavior [44]. Thus, the transportation literature supports the influence of normative effects on a wide range of behaviors. Besides previously discussed behaviors, studies have incorporated various types of social norms for policy acceptance behaviors. For instance, Zhang et al. [31], Liu et al. [45], and Nordfjærn and Rundmo [46] all found empirical evidence that personal norms could be used to design a policy to shift private car drivers to public transportation in China and Norway, respectively. Likewise, Hopkins et al. [47], Keizer et al. [48], and Jakovcevic and Steg [49] suggested that the normative considerations enhance the acceptance of policies, including travel demand management policies and transport pricing policies.

We have also noticed that cultural differences and the development of the local transportation system may impose heterogeneity in the social norms in the transportation field. For instance, Belgiawan et al. [50] compared the association of two types of social norms with car ownership motivation among youngsters in seven regions globally. They found a significant correlation between $\mathrm{DN}$ and car purchasing likelihood in Utrecht, Japan, and Taiwan, China, while the SN was observed to be significantly associated with the intention in Berkeley, Taiwan, China, and Beirut.

In conclusion, plenty of previous research studies have witnessed social norms as an essential determinant of various individual behaviors in transportation and other crossdisciplinary topics. However, little attention has been paid to finding the relationship between social norms and passengers' misbehavior in public transport. Thus, we argue that passenger's misbehavior in public transportation may also have the potential to be predicted by social norms, which may enhance the current understanding of low-level misbehavior in the transport literature. In a previous study, we have applied an ordinal logistic regression to explore the relationship of subjective norms, descriptive norms, and injunctive norms with the likelihood of passengers' misbehavior in public transport [51]. The present study was conducted to extend the previous research findings [51] and provide a better understanding of the social norms and sociodemographic features affecting passenger's misbehavior in public transportation.

\section{Methods}

3.1. Conceptual Model and Hypotheses. Based on the literature review, two preliminary hypothetical conceptual models are proposed, as displayed in Figure 1, with SN, PN, DN, and IN. Figure 1(a) includes the three constructs of social norms (i.e., SN, PN, and DN, labeled as SN-PN-DN specification), while Figure 1(b) combines SN and PN to be IN that is parallel to DN, labeled as IN-DN specification [41]. Considering the segmentation of norm constructs, we have proposed four norm-oriented hypotheses that are explained as follows: 


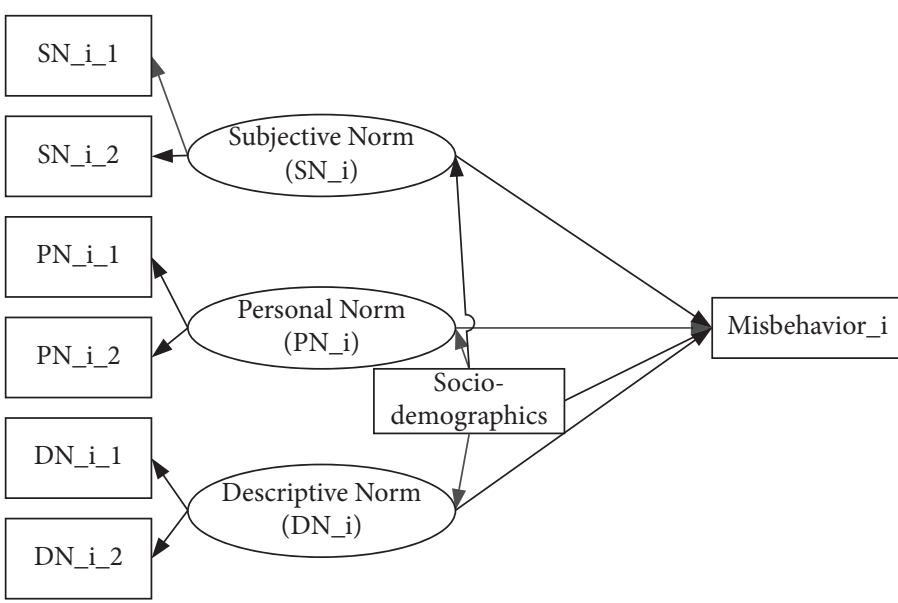

(a)

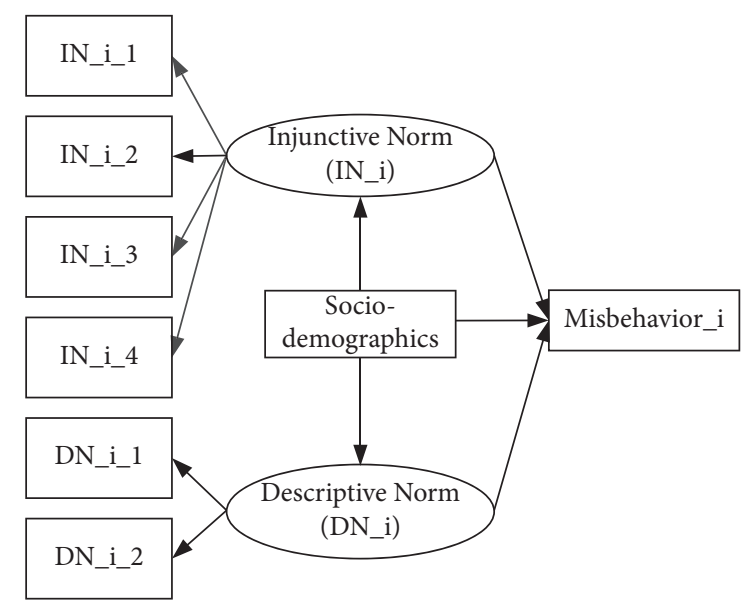

(b)

FIgURE 1: (a) Conceptual model with SN, PN, and DN; (b) conceptual model with IN and DN. Note: to distinguish the six selected misbehaviors, we use a subscript $i \in\{1,2, \ldots, 6\}$, where $1=$ eating in the carriage, $2=$ public display of affection, $3=$ sound blaster, $4=$ crosslegged sitting, $5=$ leaning against the pole, and $6=$ littering in the carriage. For each Misbehavior_i, DN_i is the descriptive norm and measured with two manifest variables, i.e., DN_1_i and DN_2_i. SN and PN in (a) and IN in (b) are similarly measured. Misbehavior_i indicates the frequency of the respondents' tendency to do the $i$ th misbehavior.

H1. SN perception contributes to decreasing misbehavior tendency

H2. PN perception contributes to decreasing misbehavior tendency

H3. IN perception contributes to decreasing misbehavior tendency

H4. DN perception contributes to decreasing misbehavior tendency

$\mathrm{H} 1$ to $\mathrm{H} 4$ share one philosophy that in case one perceives it is not acceptable to conduct a specific behavior, he/she is less likely to do such behavior, whether because it is against the public's expectation (SN) or his own value (PN) or both (IN) or because it is different from what others around him/ her do (DN).

Relationships of sociodemographics to social norm perception and misbehavior, as stated by Chen et al. [41], are reflected in hypotheses $\mathrm{H} 5$ and H6:

H5. Sociodemographic variables affect social norm perception

H6. Sociodemographic variables affect misbehavior tendency

3.2. Questionnaire and Measures. We have taken the metro carriage as the study context. A well-formatted list of misbehaviors in the metro carriage from Régie Autonome desTransports Parisiens (RATP) [52] and a UK-based study [20] has been found helpful to collect the potential misbehaviors. Scholars in travel behavior studies in China have been consulted to amend the list to reflect the cultural heterogeneity better. The initial list involves 15 candidate misbehaviors, including fare evasion, shouting or swearing at others, spitting, drinking alcohol, smoking, littering, pushing or shoving, taking up priority seats, taking more than one seat, being a sound blaster, eating, public display of affection, begging, cross-leg sitting, and leaning against the pole. Fifty passengers in Shanghai have been randomly intercepted and interviewed in metro stations to rank the most frequent misbehaviors according to their travel experience. Each candidate misbehavior has the rank as a weight in one response, i.e., if one interviewee ranked littering the most common, then the behavior would get a weight of 1 . The fifty weights for each misbehavior have been summed up. The six most common misbehaviors (i.e., with the least weight sum) have been picked out as eating in the carriage (especially food with strong smell), public display of affection (i.e., acts of physical intimacy in the view of others), sound blaster (i.e., listening to music or talking on the phone loudly), cross-legged sitting, leaning against the pole, and littering in the carriage.

A questionnaire has been prepared to collect the data for quantitative modeling. The questionnaire consists of two modules. Typical sociodemographic information (e.g., gender and age) is required to be reported in the first module. The second module is consistent with the previous research design $[53,54]$ with translation into Chinese by scholars from transportation research and linguistics. This part includes the following: (1) all the statements to measure $\mathrm{SN}, \mathrm{PN}$, and DN for each selected misbehavior (see Table 1), measured with a five-point Likert scale for the degree to which a participant agrees to a normative statement (1 and 5 being strongly agree and disagree, respectively); (2) a question on the misbehavior frequency of the respondent, tested with a four-point scale where 1 and 4 being often and never, respectively.

3.3. Structural Equation Modeling. Structural equation modeling (SEM) is a set of multivariate analysis techniques to test the theoretical hypotheses with empirical data [35]. 
TABLE 1: Statements used to measure the latent constructs.

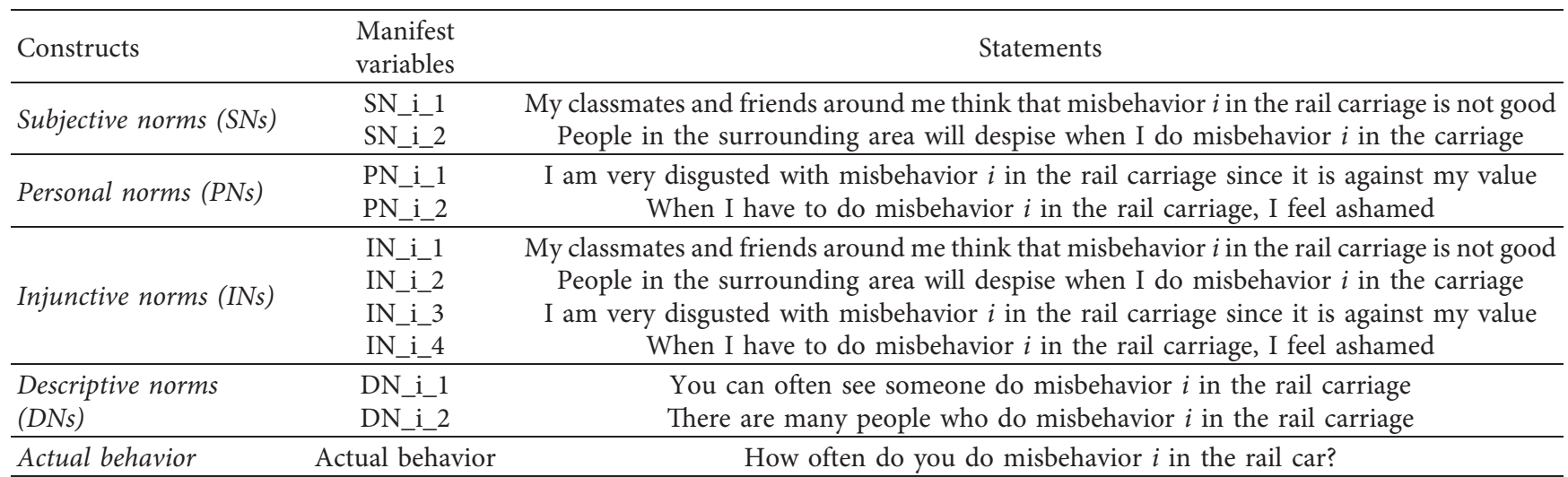

Note: $i \in\{1,2, \ldots, 6\}$, where $1=$ eating in the carriage, $2=$ public display of affection, $3=$ sound blaster, $4=$ cross-legged sitting, $5=$ leaning against the pole, and $6=$ littering in the carriage. The present study follows the social norm taxonomy by Thøgersen [33], injunctive norms (INs) could be divided into subjective norms (SNs) and personal norms (PNs), so the statements adopted for IN are the union of those for SN and PN, though recoded.

SEM can simultaneously handle several endogenous and exogenous variables to measure hypothetical latent constructs and to examine the underlying relationships between or in endogenous and exogenous latent variables, respectively $[35,55,56]$. SEM outperforms the multiple linear regression to reject the false null hypothesis [54]. The textbook by Kline [57] provides an excellent reference to the theoretical and practical aspects of SEM.

The SEM approach fits the present study well, given that it involves both latent variables (i.e., types of social norms) and multiple interrelated dependencies (i.e., the sociodemographic features and the actual behavior of the respondents). As a confirmatory method, SEM is guided by a priori theory, which is then empirically tested. Thus, we have proposed our preliminary conceptual models according to the literature review. The full model of the preliminary hypotheses with both measurement and path parts is displayed in the schematic diagram (see Figure 1). The connections are then tested with the SEM approach.

Various software tools are available to conduct structural equation modeling, but $\mathrm{R}$ statistical software, with its open access availability, is potentially beneficial for the analysis. $\mathrm{R}$ project can be downloaded free from its website (https:// www.r-project.org). The lavaan package, with its unique features for SEM $[58,59]$, is used in R project with its latest updated version to get the desirable results. For detailed information about lavaan package [60], readers are recommended to visit the website of lavaan (https://lavaan.org).

3.4. Data Collection. Bucciol et al. [61] found that younger adults are more likely to misbehave in public transport, such as fare evasion. Following this, a random sample from students at Tongji University, Shanghai, China, in the year 2014, was set as the targeted sample. A total of 350 college students were asked to fill in a paper-based questionnaire. Their response was then entered into an electronic format by two students and cross-checked to avoid any entry mistakes. A 300-valid-response sample was obtained after the data screening procedure and used in the following analysis. The deletion of 43 cases was due to data integrity (i.e., unfinished questionnaire), while the 7 responses were distinguished as unengaged responses (i.e., answers lack variation for Likert scale questions) and dropped. The minimum sample size required for parameter values of medium anticipated effect size (0.5) and desired statistical power of 0.9 was 200 for two latent variables at six observed variables at a 0.05 level of significance. The minimum sample size to detect the effect is 30 . Thus, the sample size is justified as acceptable to estimate the structure and compare differences across demographical groups $[62,63]$. No outlier was detected for the cleaned dataset.

\section{Results}

4.1. Sociodemographic Profiles of the Respondents. Table 2 provides the profile of the participants. Boys dominantly participated in the survey with $72 \%$ as compared to girls with $28 \%$. The sample represents the gender-based distribution of students at Tongji University, considering the newly enrolled students' official gender composition in 2019 to be male : female $=63.4 \%: 36.6 \%$ [64], which is steady over the years. The survey involved most young adults around the age of 20 , with the adult participants over 20 years old being 57.7\%. Among all validated respondents, $78 \%$ were undergraduates, $19.3 \%$ were master students, and $2.7 \%$ were pursuing a doctorate. Most of the sampled students were studying in their third year of university education, constituting a percentage of $44 \%$. On the contrary, only $1 \%$ was studying in the fifth year of university education. The study year distribution implied that over $80 \%$ of the participants should have stayed in Shanghai for more than one year when surveyed; they should be metro users, considering Shanghai's developed public transportation network.

4.2. Descriptive Statistics of Measures. Table 3 presents the descriptive statistics for the behavioral and social norm measures. The three items for DN and actual behavior are 
norms. The mean value for the misbehavior frequency statement is between 1.29 (between never and rare) and 3.09 (slightly larger than occasionally), with littering in the carriage and sound blaster to be most rare, leaning against the pole to be the most frequent, and cross-legged sitting and public display of affection to be comparatively equal in the reported frequency. Compared with the other five behaviors, littering in the carriage also has the smallest standard deviation (SD), indicating that the data are mostly intensively distributed and further confirm the lower frequency of the behavior. On the contrary, leaning against the pole, the largest mean, together with mediate SD indicates that it is more frequent for the respondents to lean against the pole. It may be due to the crowdedness in the carriage, especially during peak hours, when leaning against the pole can reduce physical fatigue at least to some extent.

The normative statements also show sufficient variation in intra- and interbehaviors. With 3 points as the middle point of the 5-point Likert scale, all six norm statements for littering in the carriage below 3 indicate that such behavior is mostly not accepted by the public. For cross-legged sitting and leaning against the pole, all the mean scores of the statements are between 3 and 4, i.e., such behaviors are regarded as acceptable to some extent. The other three behaviors (i.e., eating in the carriage, public display of affection, and sound blaster) witnessed a conflict between the IN and the DN. Taking sound blaster as an example, all SN and PN statements have a mean score around 2, indicating that, on average, respondents perceived a normative pressure not to be a sound blaster, while the DN with a mean score equal to or larger than 3 means that it is not uncommon to see many sound blasters in the carriage.

Structural equation modeling most commonly adopts a standard maximum likelihood (ML) estimation, which assumes multivariate normality [57]. Both univariate and multivariate normalities of the variables are tested prior to the estimation. According to the descriptive statistics in Table 3, the responses to each item are intuitively skewed. The Shapiro-Wilk test is applied to further test the univariate normality of each item and concludes that every distribution is nonnormal. The joint distributions of all variables for each behavior are tested with Mardia's multivariate skewness and kurtosis tests [65]. The multivariate normality test results are listed in Table 3 for each behavior, from which we can verify that the distribution of the responses is against the assumption that they are joint normally distributed [65]. A special estimation technique is needed to manage the failure of multivariate normal distribution, which will be discussed in Section 4.4.

4.3. Reliability and Validity of Latent Constructs. The reliability of the latent constructs is assessed with Cronbach's alpha and composite reliability. Cronbach's alpha value ranges from 0 to 1 . The closer the value of alpha near to 1 , the greater the internal consistency of the item in the construct $[42,66]$. As another measure of internal consistency reliability, composite reliability (CR) does not assume equally weighted indicator loadings, which is different from
Cronbach's alpha. According to [36], CR should be above 0.70 as a general guideline.

The convergent reliability is evaluated by calculating the average variance extracted (AVE, also referred to as communality). AVE measures the average percentage of variation explained among the construct items, with a threshold value of 0.5 [67]. Discriminant validity is the degree to which measures of different traits are unrelated. If the AVE's square root for one construct is higher than all its correlations with other constructs, appropriate discriminant validity is reached [68]. The correlation among constructs was calculated with the heterotrait-monotrait ratio of correlations (HTMT) approach $[69,70]$. Convergent reliability and discriminant validity are both tested with SmartPLS.

Reliability and validity results for the two model specifications are reported in Tables 4 and 5, respectively. For the SN-PN-DN specification, the construction of the normative traits is acceptable except for the composite reliability of the $\mathrm{DN}$ for cross-legged sitting (larger than 1) and the AVE of the SN for eating in the carriage (less than 0.5). However, the discriminant validity principle is severely violated between the $\mathrm{SN}$ and PN, which means SN and PN cannot be discriminated according to statistics. As for the IN-DN specification, all reliability and validity indicators are well followed, except for the AVE of the SN for eating in the carriage, which is marginally below the threshold value of 0.5 . Hence, the following analysis would be conducted under the IN-DN specification.

4.4. Path Analysis. We have followed the R lavaan package guide to estimate each behavior's structural equation model [58]. As revealed in Section 4.2, the items are suffering from nonnormality. Even though the parameter estimate values are generally not affected [71], the large chi-square and small standard error issue due to the assumption of nonnormality violation needing corrections to avoid the likelihood of models are easily rejected or a large type I error [72, 73]. In the present study, the correction is conducted via a maximum likelihood estimation with robust standard errors and a Satorra-Bentler scaled test statistic (namely, MLM estimator in lavaan), which is regarded as a good general approach to treat nonnormality $[58,74,75]$. The routine model fit indicators and the unstandardized and standardized robust estimates are reported in Tables 6 and 7, respectively. According to the recommended cutoff values [49, 57], all the models fit the data well.

As our sample consists of the young population and most of them are students, it is not surprising to find only the influence of gender as one sociodemographic feature was successfully incorporated in our model. Nevertheless, this study suggests incorporating other sociodemographic differences in the model for future studies on a more general passenger population. We found the significant effect of gender only for eating in the carriage and cross-legged sitting behaviors.

As displayed in Table 7 and Figure 2, we have identified two types of structures, i.e., with or without gender. Comparing the two models, a significant effect of gender is 
TABLE 4: Reliability and validity test results for the SN-PN-DN specification.

\begin{tabular}{|c|c|c|c|c|c|c|}
\hline & Cronbach's alpha & Composite reliability & AVE & \multicolumn{3}{|c|}{ Discriminant validity } \\
\hline Eating in the carriage & & & & SN1 & PN1 & DN1 \\
\hline SN1 & 0.6 & 0.61 & 0.44 & 0.66 & 0.98 & 0.12 \\
\hline PN1 & 0.73 & 0.74 & 0.58 & 0.98 & 0.76 & 0.14 \\
\hline DN1 & 0.78 & 0.78 & 0.66 & 0.12 & 0.14 & 0.81 \\
\hline Public display of affection & & & & SN2 & PN2 & $\mathrm{DN} 2$ \\
\hline SN2 & 0.7 & 0.71 & 0.60 & 0.78 & 0.86 & 0.12 \\
\hline PN2 & 0.75 & 0.76 & 0.76 & 0.86 & 0.87 & 0.14 \\
\hline DN2 & 0.76 & 0.76 & 0.62 & 0.12 & 0.14 & 0.78 \\
\hline Sound blaster & & & & SN3 & PN3 & DN3 \\
\hline SN3 & 0.74 & 0.74 & 0.59 & 0.77 & 0.89 & 0.24 \\
\hline PN3 & 0.76 & 0.77 & 0.64 & 0.89 & 0.80 & 0.21 \\
\hline DN3 & 0.82 & 0.84 & 0.70 & 0.24 & 0.21 & 0.84 \\
\hline Cross-legged sitting & & & & SN4 & PN4 & DN4 \\
\hline SN4 & 0.84 & 0.83 & 0.72 & 0.85 & 0.96 & 0.28 \\
\hline PN4 & 0.9 & 0.90 & 0.81 & 0.96 & 0.90 & 0.25 \\
\hline $\mathrm{DN} 4$ & 0.89 & 1.00 & 0.80 & 0.28 & 0.25 & 0.90 \\
\hline Leaning against the pole & & & & SN5 & PN5 & DN5 \\
\hline SN5 & 0.87 & 0.87 & 0.77 & 0.88 & 0.90 & 0.15 \\
\hline PN5 & 0.87 & 0.88 & 0.78 & 0.90 & 0.88 & 0.13 \\
\hline DN5 & 0.78 & 0.78 & 0.63 & 0.15 & 0.13 & 0.79 \\
\hline Littering in the carriage & & & & SN6 & PN6 & DN6 \\
\hline SN6 & 0.80 & 0.80 & 0.71 & 0.84 & 0.87 & 0.09 \\
\hline PN6 & 0.76 & 0.76 & 0.62 & 0.87 & 0.79 & 0.07 \\
\hline DN6 & 0.88 & 0.91 & 0.84 & 0.09 & 0.07 & 0.91 \\
\hline
\end{tabular}

The bold values on the diagonal of the discriminant validity columns are the squared root of AVE of the corresponding normative construct; the off-diagonal values are its correlation coefficients with other normative constructs.

TABLE 5: Reliability and validity test results for the IN-DN specification.

\begin{tabular}{|c|c|c|c|c|c|}
\hline \multirow{2}{*}{$\begin{array}{l}\text { Latent constructs } \\
\text { Eating in the carriage }\end{array}$} & \multirow[t]{2}{*}{ Cronbach's alpha } & \multirow[t]{2}{*}{ Composite reliability } & \multirow[t]{2}{*}{ AVE } & \multicolumn{2}{|c|}{$\begin{array}{c}\text { Discriminant } \\
\text { validity }\end{array}$} \\
\hline & & & & IN1 & DN1 \\
\hline IN1 & 0.80 & 0.80 & 0.49 & 0.70 & 0.13 \\
\hline DN1 & 0.78 & 0.79 & 0.66 & 0.13 & 0.81 \\
\hline Public display of affection & & & & IN2 & $\mathrm{DN} 2$ \\
\hline IN2 & 0.81 & 0.81 & 0.52 & 0.72 & 0.14 \\
\hline $\mathrm{DN} 2$ & 0.76 & 0.79 & 0.62 & 0.14 & 0.78 \\
\hline Sound blaster & & & & IN3 & DN3 \\
\hline IN3 & 0.83 & 0.84 & 0.56 & 0.75 & 0.24 \\
\hline DN3 & 0.82 & 0.83 & 0.70 & 0.24 & 0.84 \\
\hline Cross-legged sitting & & & & IN4 & DN4 \\
\hline IN4 & 0.92 & 0.92 & 0.74 & 0.86 & 0.27 \\
\hline DN4 & 0.89 & 0.90 & 0.80 & 0.27 & 0.89 \\
\hline Leaning against the pole & & & & IN5 & DN5 \\
\hline IN5 & 0.91 & 0.91 & 0.72 & 0.85 & 0.15 \\
\hline DN5 & 0.78 & 0.80 & 0.63 & 0.15 & 0.79 \\
\hline Littering in the carriage & & & & SN6 & DN6 \\
\hline IN6 & 0.85 & 0.85 & 0.59 & 0.76 & 0.08 \\
\hline DN6 & 0.88 & 0.88 & 0.84 & 0.08 & 0.91 \\
\hline
\end{tabular}

The bold values on the diagonal of the discriminant validity columns are the squared root of AVE of the respective normative construct; the off-diagonal values are its correlation coefficients with other normative constructs.

observed concerning two of the six misbehaviors, i.e., eating in the carriage and cross-legged sitting.

The proposed hypothesis (H1) and hypothesis (H2) assuming the influence of SN/PN perception on misbehavior cannot be accepted due to $\mathrm{SN}$ and PN's higher interdependence and the construct's validity issues explained in
Table 3. Consistent with hypothesis (H3), IN was significantly affecting the frequency of conducting misbehavior by the passengers in a carriage (see the $P$ values for the IN $\longrightarrow$ misbehavior links in Table 7). Likewise, the results in Table 7 suggest that hypothesis (H4) cannot be rejected as $\mathrm{DN}$ was found to influence the frequency of conducting 
TABLE 6: The goodness-of-fit statistics.

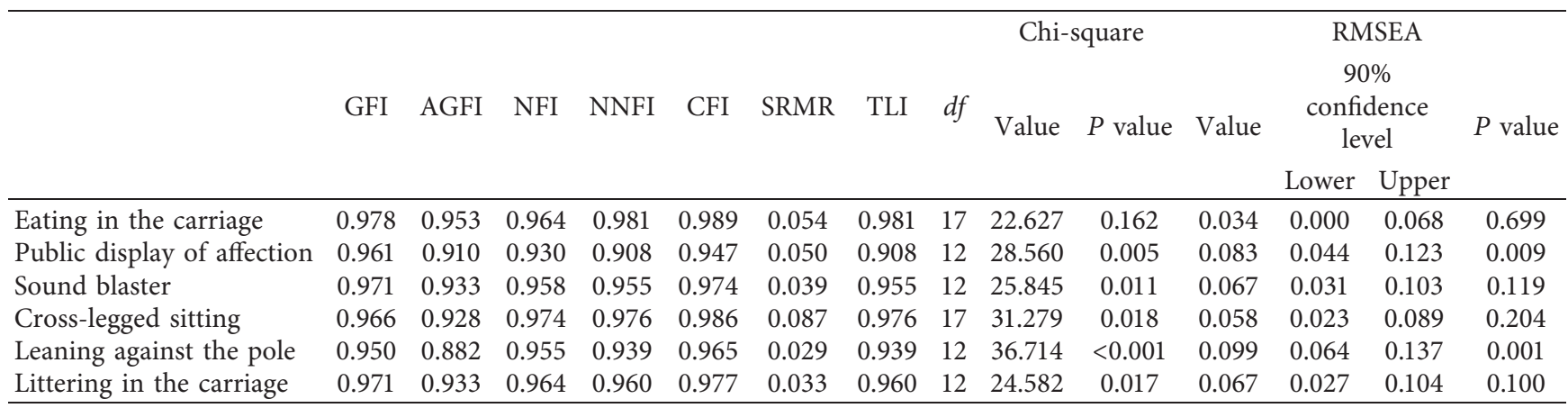

GFI: goodness of fit index, $\geq 0.95$; AGFI: adjusted goodness of fit, $\geq 0.95$; NFI: normed fit index, $\geq 0.95$; NNFI: nonnormed fit index, $\geq 0.95$; CFI: comparative fit index, $\geq 0.90$; SRMR: standardized root of the mean-square residual, $<0.08$; TLI: Tucker-Lewis index, $\geq 0.95$; $d f$ : degree of freedom; RMSEA: root-mean-square error of approximation, $<0.08$.

TABLE 7: Path analysis results for all behaviors.

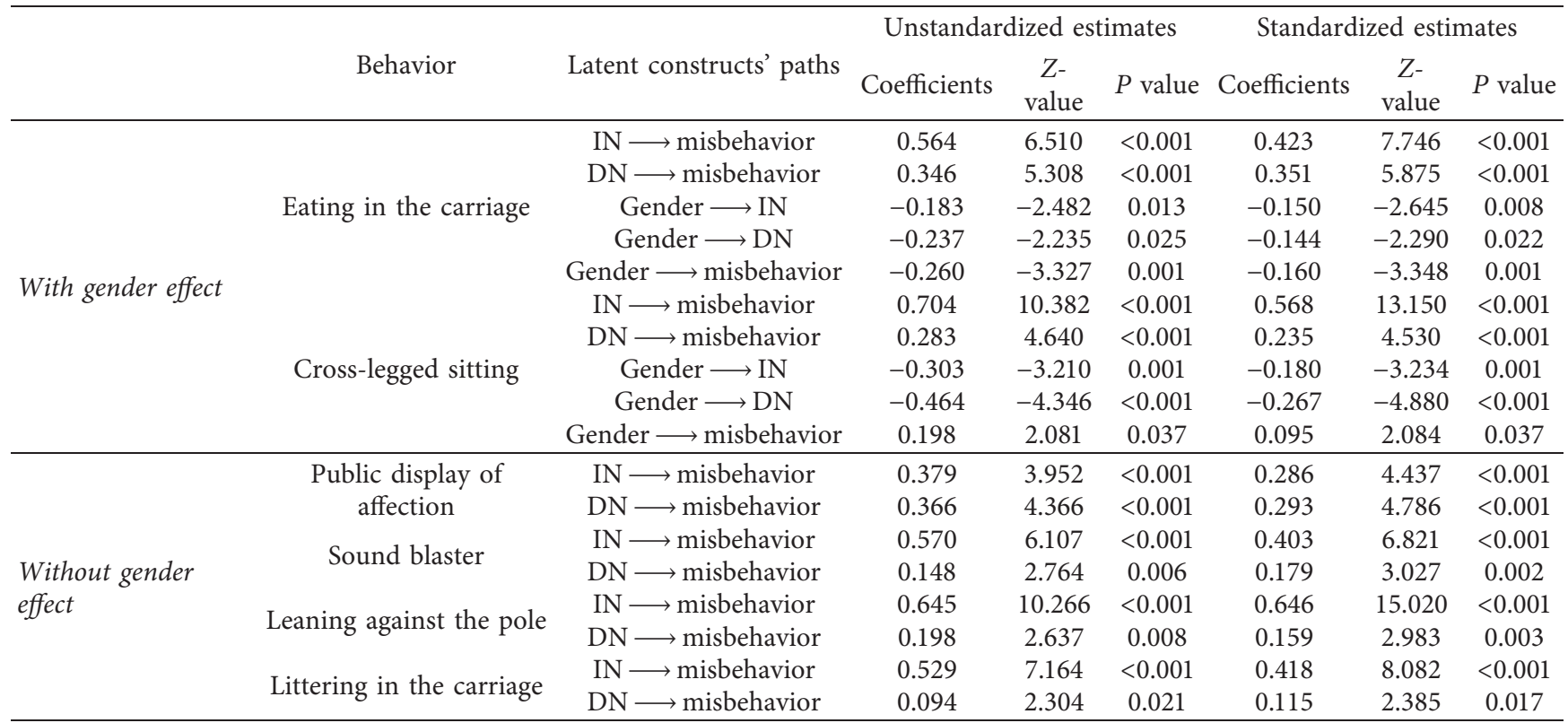

IN: injunctive norms; DN: descriptive norms. Gender is dichotomous, with 0 to be female and 1 to be male. Only significant links are reported in the table for the sake of clarity.

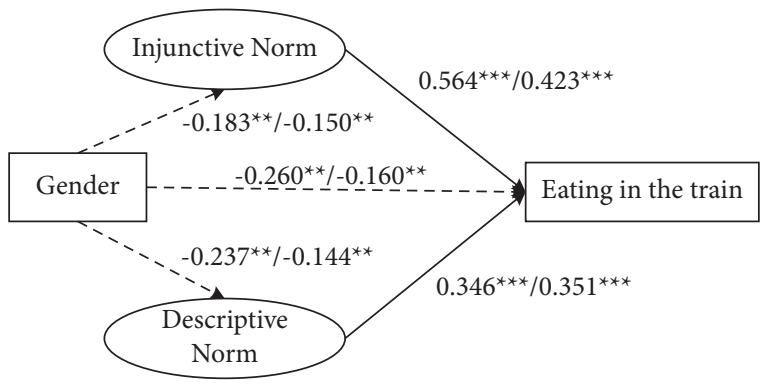

(a)

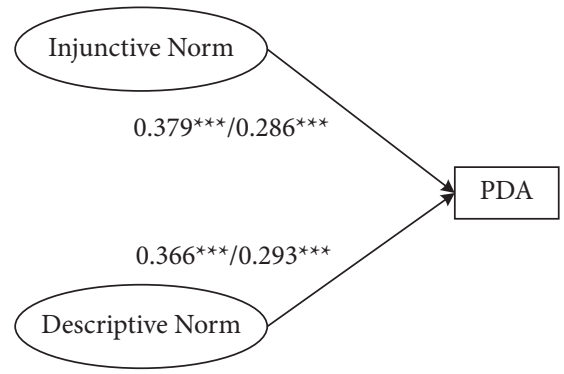

(b)

Figure 2: Examples of the estimated path structures: (a) structure with gender and (b) structure without gender. Note: for each path, we show unstandardized coefficient/standardized coefficient, ${ }^{* * *}$ significant at the 0.001 level and ${ }^{* *}$ significant at the 0.01 level. The dashed line indicates a negative effect, while the solid line is for a positive effect. 
misbehaviors by the passengers significantly. Interestingly, this study found that hypothesis (H5) and hypothesis (H6) assuming the gender-based significant influence on misbehaviors cannot be rejected for at least two misbehaviors (i.e., eating in the carriage and cross-legged sitting) considered in the present study, as shown in Table 7 (see the $P$ values for the gender $\longrightarrow$ misbehavior links). However, H5 and $\mathrm{H} 6$ cannot be accepted for the other four misbehaviors (i.e., public display of affection, sound blaster, leaning against the pole, and littering in the carriage) considered in the present study.

Both unstandardized and standardized coefficients for the significant connections are reported in Table 7 , in line with the current study's postulated hypothesis. The link coefficients between IN/DN statements and the misbehaviors' frequency are positive regarding eating in the carriage, depicting a greater influence of IN/DN on the frequency of conducting misbehaviors. To be specific, one unit increase in the score of IN will bring a 0.423 unit increase on the misbehavior scale towards the lower misbehavior frequency end due to the negative statements used to measure the latent constructs. In terms of standardized coefficient, IN's impacts (0.423) are slightly larger than those of the DN (0.351). Similar interpretations of the IN/DN influence on misbehaviors can be drawn from the results explained in Table 7 for public display of affection, sound blaster, crosslegged sitting, leaning against the pole, and littering in the carriage.

\section{Discussion}

Table 8 shows how independents influence the dependents via different paths by distinguishing direct, indirect, and total effects, calculated from Table 7 . The results provide evidence to support the hypothesis that has been made in the early stage of the current study. Hence, hypothesis 3/hypothesis 4: IN/DN regarding misbehavior contributes to decreasing the tendency to do misbehavior that can be accepted by considering the significant effect of IN and DN for all misbehaviors, while hypothesis 5/hypothesis 6: sociodemographic variables (gender) may affect social norm perceptions/misbehaviors that are only supported for eating in the carriage and cross-legged sitting because gender effects (gender $\longrightarrow$ IN/DN and gender $\longrightarrow$ misbehavior) are significant only in eating in the carriage and cross-legged sitting. However, hypothesis $1 /$ hypothesis 2 : SN/PN contributes to decreasing the tendency to do misbehavior which is not supported by the current study because of their highly interdependence nature and lack of construct validity issues, as explained in Table 3. Table 8 illustrates that all the six misbehaviors in the metro carriage are mostly influenced by social norms and demonstrate a gender heterogeneity, which will be discussed in the following section. The larger values of total indirect effects in Table 8 for eating in the carriage $(-0.114)$ and cross-legged sitting $(-0.165)$ illustrate that the norm-based mediated effect of gender has a stronger influence on reducing the tendency of such misbehaviors. In other words, males (due to negative coefficient values) have higher perceived pressure of social norms than females, and the tendency of involvement in misbehavior may largely increase or decrease due to the presence of IN and DN. Meanwhile, both eating in the carriage and cross-legged sitting have higher direct effects from the IN and DN to misbehavior compared to gender. It indicates that the IN and DN can regulate the tendency of conducting misbehavior for both genders.

5.1. The Impacts of Social Norms. We have observed that the injunctive nature of the SN and PN outperforms the difference in the source of norms that they have reflected, consistent with a previous study [33]. For all six behaviors, in terms of coefficient value, both injunctive and descriptive norms show a significant positive association with the respondent's reported misbehavior frequency, which is in line with literature studies $[32,42]$. As previously discussed, an increase in the norm constructs means the respondent is less likely to feel a robust normative effect since they more disagree with the statement that people hold a negative attitude for specific misbehavior. Hence, it is reasonable for a respondent with a higher norm construct value to be more involved in misbehavior. Comparing the discrepancy of IN and DN impacts across all the six behaviors, we have found that IN shows much stronger impacts than its descriptive counterpart in terms of coefficient magnitude, except for the public display of affection. Such a finding indicates that IN is more effective than $\mathrm{DN}$ in regulating misbehaviors in the metro carriage. To be more specific, if the targeted population realizes the high psychological cost, their misbehavior will be more reduced than only tell them how the surroundings behave. Regarding the public display of affection, the approximation of IN and DN coefficients means other passenger's approval and their actual deed are comparatively equivalent when one decides whether to show affection with his/her partner in the carriage. Such a finding may be partially viable because the respondents are sampled from young students, who are more enthusiastic and tend to show off their emotions in the public space. Though public display of affection in the public space is underresearched, we notice some recent works on the youngster's affection show-off behavior through social media. For example, with narrative research, Liu [76] found that the single group has a stereotype (which could be seen as the perceived DN of the singles) that the lovers are more likely to display affection online $[76,77]$. Thus, we argue that, for a culture that regards PDA as a nuisance, it is comparatively essential to discourage the occurrence of such behavior in both real and virtual worlds.

5.2. The Gender Heterogeneity. Gender heterogeneity is detected on both social norms and behavior frequency across the six misbehaviors investigated in the present study. According to the calculated effects, male passengers are less likely to eat in the carriage or sit with their legs crossed (since the total gender effects for eating in the carriage and crosslegged sitting are both negatives). According to our understanding, such an impact consists of two resources. The direct impacts of gender may come from males' physical 


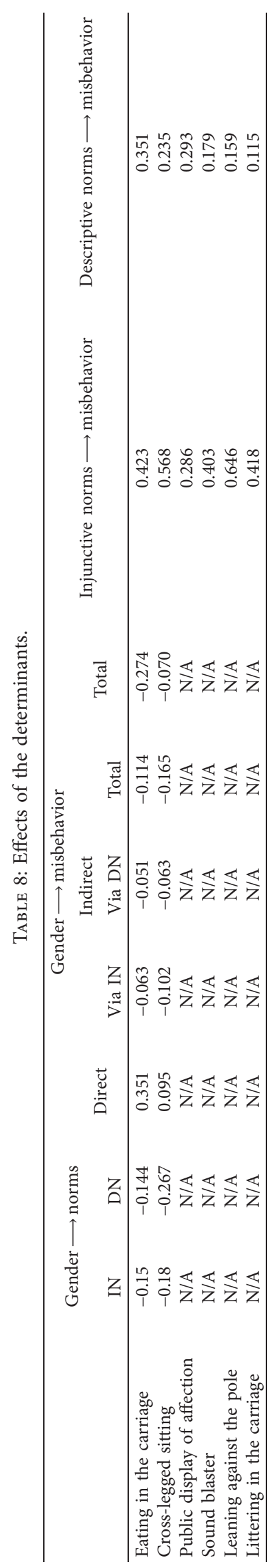


advantage over females and are consistent with the total effect. The indirect effect, which exceeds the direct one, is mediated by norms. We have found that the value of the normative construct for male passengers is lower than that for the female respondents (the gender $\longrightarrow$ norms effects are negative), which means that male passengers, on average, perceived a higher pressure not to misbehave such as eating in the carriage or cross-legged sitting. In other words, norms amplify the gender difference in conducting different misbehaviors since IN and DN's coefficients are positive.

Meanwhile, it is worth noting that male and female passengers do not behave statistically differently for the other four misbehaviors since the gender variable is not significant, which could be seen as another form of gender heterogeneity when all the six misbehaviors are compared with each other. Similar findings could be seen in the work proposed by Jing [77], in which she also reported that no gender heterogeneity was detected in the online public display of affection behavior. The findings are consistent with some of the previous studies revealing the difference between males and females in norms' perception and actual behaviors in various transportation settings $[36,37,46]$. Hence, we argue that gender heterogeneity is behavior specific and should be further investigated and seriously considered when designing misbehavior-regulation policy.

\section{Conclusions}

Transit passengers' misbehaviors such as eating in the carriage and public display of affection seem not severe initially, but they can seriously degrade transit image and trip experience to hinder transit ridership from retaining or increasing. Considering the high cost of strict enforcement against such misbehaviors, this research provides an insight into the potential of some softer and more active measures to regulate such behaviors from the social-psychological perspective [78]. Taking Shanghai Metro as the study context, six misbehaviors are selected on which the effect of social norms, from both injunctive and descriptive perspectives, is tested with SEM based on empirical data collected among college students. The estimated model also reveals gender heterogeneity on the normative constructs as well as the behavior frequency.

The study contributes to the existing literature in several ways. Firstly, it brought the problem of passenger misbehavior in the metro carriage, which negatively influences the passenger's travel experience but is barely discussed, to the spotlight. Secondly, it proposed a perspective to analyze the motivation of misbehaving from the social-psychological approach. Thirdly, empirical evidence is provided on the strength difference of injunctive norms and descriptive norms regulating such behaviors.

The present study has justified the association between various social norms and different types of misbehaviors in the metro carriage. The findings imply that a social normbased intervention strategy should be promising to reduce the occurrence of such unacceptable behaviors $[43,79]$ and thus improve the metro travel experience. As for the policymakers' implementation concern from either the authority or operator, while poster advertisement such as the Paris metro case is worthwhile for trial, messages directly sent to the individual passenger may better ensure the delivery rate and attract their attention. We further suggest that the content of the persuasive message and the intervention time need to be carefully designed to avoid any possible reactance evoked by an external force $[43,79]$.

Future research is suggested to various misbehaviors common in different cultural and economic backgrounds, such as manspreading and PDA. Also, social norms may change over time and vary among countries [29], and this research can be correspondingly extended longitudinally or laterally. We have focused on the power of different social norms and the fundamental individual demographics, which indeed show a significant influence on the investigated misbehavior. However, we also noted many more factors (e.g., attitude and the perceived service quality on the metro) that have been applied in other behavior modeling contexts could be added to the list of determinants to enrich the understanding of such misbehaviors. Further studies are also required to understand the differences in the reach of various misbehaviors. For example, sound blasters in public transportation have a long-range impact, and the frequency of their occurrence might also affect passengers in the whole carriage, compared to other misbehaviors, i.e., littering, which has a limited direct impact on passengers. Thus, passengers' perceived severity regarding various misbehaviors and the inconvenience attached to them should be considered in future studies.

The impacts of social norms on the misbehavior in the metro carriage are confirmed in the current study, which helps persuasive measure design from the social-psychological perspective. We have noted that some similar propaganda campaigns had been implemented in Japan, France, and the United States. However, the acceptance and effectiveness of such actions, which are essential and valuable for policy evaluation and future improvement, are barely seen in the existing literature. Finally, as an explanatory study, we argue that it is reasonable to have educated college students as the present study sample. However, to obtain a more general conclusion, extending the population to the metro passengers with a justified sample size and sociodemographic composition is necessary.

\section{Data Availability}

The data would be available to those who are interested in the work by application to the corresponding author.

\section{Conflicts of Interest}

The authors declare that they have no conflicts of interest.

\section{Authors' Contributions}

DZ conceptualized the study, provided the methodology, collected the data, performed formal analysis, wrote the 
original draft, reviewed and edited the article, and contributed to funding acquisition. FB searched and reviewed the literature, formulated and estimated the model, wrote the original draft, and reviewed and edited the article. SM formulated and estimated the model and wrote and edited the article. HX conceptualized the study, reviewed and edited the article, and contributed to funding acquisition. HJ collected the data and reviewed and edited the article. LL conceptualized the study, reviewed and edited the article, and contributed to funding acquisition.

\section{Acknowledgments}

This work was funded by the National Natural Science Foundation of China (nos. 71701031, 71901040, and 61374193), the Fundamental Research Funds for the Central Universities (DUT18RC (4)049 and CHD 300102210525), and the Natural Science Basic Research Program of Shaanxi, China (Grant no. 2019JQ-442).

\section{References}

[1] M. Russell, R. Price, L. Signal, J. Stanley, Z. Gerring, and J. Cumming, "What do passengers do during travel time? Structured observations on buses and trains," Journal of Public Transportation, vol. 14, no. 3, pp. 123-146, 2011.

[2] V. De, "J. Satisfaction-induced travel behaviour," Transportation Research Part F: Traffic Psychology and Behaviour, vol. 63, 2019.

[3] F. Skarin, L. E. Olsson, M. Friman, and E. Wästlund, "Importance of motives, self-efficacy, social support and satisfaction with travel for behavior change during travel intervention programs," Transportation Research Part F: Traffic Psychology and Behaviour, vol. 62, pp. 451-458, 2019.

[4] C. Boyd, C. Martini, J. Rickard, and A. Russell, "Fare evasion and non-compliance: a simple model," Journal of Transport Economics and Policy, vol. 23, pp. 189-197, 1989.

[5] A. Delbosc and G. Currie, "Why do people fare evade? A global shift in fare evasion research," Transport Reviews, vol. 39, no. 3, pp. 376-391, 2019.

[6] A. Hudson, Why Do People Play Music in Public through a Phone?-BBC News, BBC News, Portland, UK, 2011.

[7] P. Williams, The Bad Behaviours Driving Brisbane Train Passengers Nuts, ABC News, New York, NY, USA, 2017, https://www.abc.net.au/news/2017-10-16/behavioursdriving-queensland-rail-passengers-nuts/9018836.

[8] The Jakarta Post, Jakarta's MRT Guidelines Video Baffles Passengers, The Jakarta Post, Jakarta, Indonesia, 2019.

[9] CGTN. Man Sparks, "Fury for taking another passenger's train seat-CGTN," China Global Television Network (CGTN), https:// news.cgtn.com/news/3d3d514d7a457a4e79457a6333566d54/ index.html, 2019.

[10] B. Goh, China to Bar People with Bad "Social Credit" from Planes, Trains-Reuters, London, UK, 2018, https://www.reuters. com/article/us-china-credit/china-to-bar-people-with-badsocial-credit-from-planes-trains-idUSKCN1GS10S.

[11] A. Ma, A Creepy Video Shows How China Warns its Citizens to Behave or Get Punished by its Nationwide Social Credit System, Business Insider Nederland, Amsterdam, Nederland, 2019, https://www.businessinsider.nl/video-chinatrain-warns-citizens-to-behave-for-social-credit-system2018-10/?international $=$ true $\& r=U S$.
[12] Chicago Transit Authority, Courtesy Campaign, CTA, Chicago, IL, USA, 2019, https://www.transitchicago.com/ courtesy/.

[13] "Amsterdam marketing. Enjoy and respect campaign," https://iamsterdam.getbynder.com/web/39191f8035f7031d/ enjoy---respect-eng/?mediaId=34998B10-B4CF-444A9FAAA3DFF93DF4FC.

[14] X. E. Wang, "Drinking to Be banned on all subways-chinadaily.Com.Cn," China Daily, https://www.chinadaily.com.cn/ cndy/2019-10/29/content_37519064.htm, 2020.

[15] Collins English Dictionary, "Misbehaviour definition and meaning," 2019, https://www.collinsdictionary.com/ dictionary/english/misbehaviour.

[16] Merriam-Webster, "Misbehavior|definition of misbehavior by merriam-webster," 2019, https://www.merriam-webster.com/ dictionary/misbehavior.

[17] R. H. Thaler and L. Ganser, Misbehaving: The Making of Behavioral Economics, W. W. Norton, New York, NY, USA, 2015.

[18] R. A. Fullerton and G. Punj, "What is consumer misbehavior?" Advances in Consumer Research, vol. 24, no. 1, pp. 336-339, 1997.

[19] S. Tsaur, T. Cheng, and C. Hong, "Exploring tour member misbehavior in group package tours," Tourism Management, vol. 71, pp. 34-43, 2019.

[20] S. Moore, "Understanding and managing anti-social behaviour on public transport through value change: the considerate travel campaign," Transport Policy, vol. 18, no. 1, pp. 53-59, 2011.

[21] M. Friman and M. Fellesson, "Service supply and customer satisfaction in public transportation: the quality paradox," Journal of Public Transportation, vol. 12, no. 4, pp. 57-69, 2009.

[22] N. Salomonson and M. Fellesson, "Tricks and tactics used against troublesome travelers-Frontline staff's experiences from Swedish buses and trains," Research in Transportation Business \& Management, vol. 10, pp. 53-59, 2014.

[23] S. Moore, "Preventing anti-social behaviour on public transport: an alternative route," Crime Prevention and Community Safety, vol. 12, no. 3, pp. 176-193, 2010.

[24] T. P. Ali, Which CTA Misbehavior Is the Worst?-DowntownChicago, DNAinfo, New York, NY, USA, 2019, https://www. dnainfo.com/chicago/20150527/downtown/poll-which-ctamisbehavior-is-worst.

[25] L. S. Tufano, CTA Shames Rude Passengers with Brutally Honest Ad Campaign-Downtown-Chicago-DNAinfo, Dnainfo, New York, NY, USA, 2019, https://www.dnainfo.com/ chicago/20150527/downtown/cta-fights-against-train-djsmanspreading-courtesy-campaign-photos/.

[26] A. Delbosc and G. Currie, "Four types of fare evasion: a qualitative study from melbourne, Australia," Transportation Research Part F: Traffic Psychology and Behaviour, vol. 43, pp. 254-264, 2016.

[27] M. Cools, Y. Fabbro, and T. Bellemans, "Identification of the determinants of fare evasion," Case Studies on Transport Policy, vol. 6, no. 3, pp. 348-352, 2018.

[28] M. Fellesson, N. Salomonson, and A. Åberg, "Troublesome travellers-the service system as a trigger of customer misbehaviour," International Journal of Quality and Service Sciences, vol. 5, no. 3, pp. 256-274, 2013.

[29] R. N. Rimal and M. K. Lapinski, "A Re-explication of social norms, ten years later," Communication Theory, vol. 25, no. 4, pp. 393-409, 2015.

[30] R. B. Cialdini and M. R. Trost, "Social influence: social norms, conformity and compliance," in The Handbook of Social 
Psychology, D. T. Gilbert, S. T. Fiske, and G. Lindzey, Eds., p. 1085, McGraw-Hill, New York, NY, USA, 1998.

[31] D. Zhang, J.-D. Schmöcker, S. Fujii, and X. Yang, "Social norms and public transport usage: empirical study from Shanghai," Transportation, vol. 43, no. 5, pp. 869-888, 2016.

[32] R. B. Cialdini, R. R. Reno, and C. A. Kallgren, "A focus theory of normative conduct: recycling the concept of norms to reduce littering in public places," Journal of Personality and Social Psychology, vol. 58, no. 6, pp. 1015-1026, 1990.

[33] J. Thøgersen, "Norms for environmentally responsible behaviour: an extended taxonomy," Journal of Environmental Psychology, vol. 26, no. 4, pp. 247-261, 2006.

[34] M. N. Borhan and A. N. H. Ibrahim, "Miskeen. Extending the theory of planned behaviour to predict the intention to take the new high-speed rail for intercity travel in Libya: assessment of the influence of novelty seeking, trust and external influence," Transportation Research Part A: Policy and Practice, vol. 130, pp. 373-384, 2019.

[35] Q. Jiang, H. Huang, W. Zhao, F. Baig, J. Lee, and P. Li, "Intention of risk-taking behavior at unsignalized intersections under the connected vehicle environment," IEEE Access, vol. 9, p. 1, 2021.

[36] K. Alzahrani, A. Hall-Phillips, and A. Z. Zeng, "Applying the theory of reasoned action to understanding consumers' intention to adopt hybrid electric vehicles in Saudi arabia," Transportation, vol. 46, no. 1, pp. 199-215, 2019.

[37] M. Barth, P. Jugert, and I. Fritsche, "Still underdetected-social norms and collective efficacy predict the acceptance of electric vehicles in Germany," Transportation Research Part F: Traffic Psychology and Behaviour, vol. 37, pp. 64-77, 2016.

[38] Ö. Simsekoglu and C. Klöckner, "Factors related to the intention to buy an E-bike: a survey study from Norway," Transportation Research Part F: Traffic Psychology and Behaviour, vol. 60, pp. 573-581, 2019.

[39] J. Thøgersen and J. V. Ebsen, "Perceptual and motivational reasons for the low adoption of electric cars in Denmark," Transportation Research Part F: Traffic Psychology and Behaviour, vol. 65, pp. 89-106, 2019.

[40] R. I. McDonald and C. S. Crandall, "Social norms and social influence," Current Opinion in Behavioral Sciences, vol. 3, pp. 147-151, 2015.

[41] H.-Y. W. Chen, B. Donmez, L. Hoekstra-Atwood, and S. Marulanda, "Self-reported engagement in driver distraction: an application of the theory of planned behaviour," Transportation Research Part F: Traffic Psychology and Behaviour, vol. 38, pp. 151-163, 2016.

[42] H. Zhou, S. B. Romero, and X. Qin, "An extension of the theory of planned behavior to predict pedestrians' violating crossing behavior using structural equation modeling," Accident Analysis \& Prevention, vol. 95, pp. 417-424, 2016.

[43] H. S. Kim, "The role of legal and moral norms to regulate the behavior of texting while driving," Transportation Research Part F: Traffic Psychology and Behaviour, vol. 52, pp. 21-31, 2018.

[44] L. Gao, Y. Ji, X. Yan, Y. Fan, and W. Guo, "Incentive measures to avoid the illegal parking of dockless shared bikes: the relationships among incentive forms, intensity and policy compliance," Transportation, vol. 48, 2020.

[45] D. Liu, H. Du, F. Southworth, and S. Ma, "The influence of social-psychological factors on the intention to choose lowcarbon travel modes in tianjin, China," Transportation Research Part A: Policy and Practice, vol. 105, pp. 42-53, 2017.
[46] T. Nordfjærn and T. Rundmo, "Acceptance of disincentives to driving and pro-environmental transport intentions: the role of value structure, environmental beliefs and norm activation," Transportation, vol. 46, no. 6, pp. 2381-2396, 2019.

[47] D. Hopkins, E. García Bengoechea, and S. Mandic, "Adolescents and their aspirations for private car-based transport," Transportation, vol. 48, 2019.

[48] M. Keizer, R. J. Sargisson, M. van Zomeren, and L. Steg, "When personal norms predict the acceptability of push and pull car-reduction policies: testing the ABC model and lowcost hypothesis," Transportation Research Part F: Traffic Psychology and Behaviour, vol. 64, pp. 413-423, 2019.

[49] A. Jakovcevic and L. Steg, "Sustainable transportation in Argentina: values, beliefs, norms and car use reduction," Transportation Research Part F: Traffic Psychology and Behaviour, vol. 20, pp. 70-79, 2013.

[50] P. F. Belgiawan, J. D. Schmöcker, M. Abou-Zeid et al., "Car ownership motivations among undergraduate students in China, Indonesia, Japan, Lebanon, Netherlands, taiwan, and USA," Transportation, vol. 41, no. 6, pp. 1227-1244, 2014.

[51] D. Zhang, B. Farrukh, Z. Dong, and F. Baig, "The impacts of social norms on passengers' misbehavior in the metro carriage," in Proceedings of the 20th COTA International Conference of Transportation Professionals, Xi'an, China, August 2020.

[52] P. Allen, "French admit they ARE rude as Paris metro bosses launch poster campaign of hilarious anti-social animals encourage "La civilité"," Daily Mail, https://www.dailymail.co. uk/news/article-2179450/French-admit-ARE-rude-stroppyParis-public-transport-bosses-launch-campaign-civility.html, 2021.

[53] X. Sun, S. Feng, and J. Lu, "Psychological factors influencing the public acceptability of congestion pricing in China," Transportation Research Part F: Traffic Psychology and Behaviour, vol. 41, no. 1, pp. 104-112, 2016.

[54] K. A. Bollen, Structural Equations with Latent Variables, John Wiley \& Sons, Hoboken, NJ, USA, 1989.

[55] L. A. Hayduk and L. Littvay, "Should researchers use single indicators, best indicators, or multiple indicators in structural equation models?" BMC Medical Research Methodology, vol. 12, no. 1, p. 159, 2012.

[56] S. Tao, S. Y. He, and J. Thøgersen, "The role of car ownership in attitudes towards public transport: a comparative study of guangzhou and Brisbane," Transportation Research Part F: Traffic Psychology and Behaviour, vol. 60, pp. 685-699, 2019.

[57] R. B. Kline, Principles and Practices of Structural Equation Modelling, Guilford Press, New York, NY, USA, 2015.

[58] K. Gana and G. Broc, Structural Equation Modeling with Lavaan, John Wiley \& Sons, Hoboken, NJ, USA, 2018.

[59] Y. Rosseel, "The lavaan tutorial," The lavaan tutorial, vol. 37, 2019, http://lavaan.ugent.be/.

[60] Y. Rosseel, "Lavaan: an R package for structural equation modeling," Journal of Statistical Software, vol. 48, no. 2, 2012.

[61] A. Bucciol, F. Landini, and M. Piovesan, "Unethical behavior in the field: demographic characteristics and beliefs of the cheater," Journal of Economic Behavior \& Organization, vol. 93, pp. 248-257, 2013.

[62] S. Dinesh, G. Rejikumar, and G. S. Sisodia, "An empirical investigation into carpooling behaviour for sustainability," Transportation Research Part F: Psychology and Behaviour, vol. 77, pp. 181-196, 2021.

[63] E. R. Dickinson, J. L. Adelson, and J. Owen, "Gender balance, representativeness, and statistical power in sexuality research 
using undergraduate student samples," Archives of Sexual Behavior, vol. 41, no. 2, pp. 325-327, 2012.

[64] T. University, Tongji Fresh Students Big Data, Tongji University, Shanghai, China, 2019, https://mp.weixin.qq.com/s/ TlueeWPVRIB-orAn1WPCig.

[65] S. Korkmaz, D. Goksuluk, and G. Zararsiz, "MVN: an R package for assessing multivariate normality," The R Journal, vol. 6, pp. 151-162, 2014.

[66] J. C. Nunnally and I. H. Bernstein, Psychometric Theory, McGraw-Hill, New York, NY, USA, 3rd edition, 1994.

[67] E. F. Sam, K. Brijs, S. Daniels, T. Brijs, and G. Wets, "Construction and validation of a public bus passenger safety scale," Transportation Research Part F: Traffic Psychology and Behaviour, vol. 66, pp. 47-62, 2019.

[68] C. Fornell and D. F. Larcker, "Evaluating structural equation models with unobservable variables and measurement error," Journal of Marketing Research, vol. 18, no. 1, pp. 39-50, 1981.

[69] J. Henseler, C. M. Ringle, and M. Sarstedt, "A new criterion for assessing discriminant validity in variance-based structural equation modeling," Journal of the Academy of Marketing Science, vol. 43, no. 1, pp. 115-135, 2015.

[70] A. S. Kang, K. Jayaraman, K. Soh, and W. P. Wong, "Convenience, flexible service, and commute impedance as the predictors of drivers' intention to switch and behavioral readiness to use public transport," Transportation Research Part F: Traffic Psychology and Behaviour, vol. 62, pp. 505-519, 2019.

[71] J. F. Finch, S. G. West, and D. P. MacKinnon, "Effects of sample size and nonnormality on the estimation of mediated effects in latent variable models," Structural Equation Modeling: A Multidisciplinary Journal, vol. 4, no. 2, pp. 87-107, 1997.

[72] H. K. Suman, N. B. Bolia, and G. Tiwari, "Perception of potential bus users and impact of feasible interventions to improve quality of bus services in Delhi," Case Studies on Transport Policy, vol. 6, no. 4, pp. 591-602, 2018.

[73] P. J. Curran, S. G. West, and J. F. Finch, “The robustness of test statistics to nonnormality and specification error in confirmatory factor Analysis," Psychological Methods, vol. 1, no. 1, pp. 16-29, 1996.

[74] L. Hu, P. M. Bentler, and Y. Kano, "Can test statistics in covariance structure analysis Be trusted?” Psychological Bulletin, vol. 112, no. 2, pp. 351-362, 1992.

[75] A. Satorra, Scaling Corrections for Chi-Square Statistics in Covariance Structure Analysis, Department of Statistics, Los Angeles, CA, USA, 1988.

[76] P. Liu, "'Show off affection": self-presentation research of college student lovers online social interaction," 2018.

[77] Y. Jing, "The cultural logic of internet behavior: taking the public displays of affections on weibo for for example," Youth Research, vol. 18, no. 3, pp. 57-63, 2016.

[78] S. Bamberg, S. Fujii, M. Friman, and T. Gärling, "Behaviour theory and soft transport policy measures," Transport Policy, vol. 18, no. 1, pp. 228-235, 2011.

[79] C. Kormos, R. Gifford, and E. Brown, "The influence of descriptive social norm information on sustainable transportation behavior," Environment and Behavior, vol. 47, no. 5, pp. 479-501, 2015. 